\title{
Low Temperature Antioxidant Activity QTL Associate with Genomic Regions Involved in Physiological Cold Stress Tolerance Responses in Rice (Oryza sativa L.)
}

\author{
Huy Phan and Michael Schläppi *(1)
}

Citation: Phan, H.; Schläppi, M. Low Temperature Antioxidant Activity QTL Associate with Genomic Regions Involved in Physiological Cold Stress Tolerance Responses in Rice (Oryza sativa L.). Genes 2021, 12, 1700. https://doi.org/10.3390/genes 12111700

Academic Editor: Bing Yang

Received: 21 September 2021

Accepted: 25 October 2021

Published: 26 October 2021

Publisher's Note: MDPI stays neutral with regard to jurisdictional claims in published maps and institutional affiliations.

Copyright: (c) 2021 by the authors. Licensee MDPI, Basel, Switzerland. This article is an open access article distributed under the terms and conditions of the Creative Commons Attribution (CC BY) license (https:/ / creativecommons.org/licenses/by/ $4.0 /)$.
Department of Biological Sciences, Marquette University, Milwaukee, WI 53233, USA; huy.phan@marquette.edu * Correspondence: michael.schlappi@marquette.edu; Tel.: +1-414-288-1480

\begin{abstract}
Boosting cold stress tolerance in crop plants can minimize stress-mediated yield losses. Asian rice (Oryza sativa L.), one of the most consumed cereal crops, originated from subtropical regions and is generally sensitive to low temperature environments. Within the two subspecies of rice, JAPONICA, and INDICA, the cold tolerance potential of its accessions is highly variable and depends on their genetic background. Yet, cold stress tolerance response mechanisms are complex and not well understood. This study utilized 370 accessions from the Rice Diversity Panel 1 (RDP1) to investigate and correlate four cold stress tolerance response phenotypes: membrane damage, seedling survivability, and catalase and anthocyanin antioxidative activity. Most JAPONICA accessions, and admixed accessions within JAPONICA, had lower membrane damage, higher antioxidative activity, and overall, higher seedling survivability compared to INDICA accessions. Genome-wide association study (GWAS) mapping was done using the four traits to find novel quantitative trait loci (QTL), and to validate and fine-map previously identified QTL. A total of 20 QTL associated to two or more traits were uncovered by our study. Gene Ontology (GO) term enrichment analyses satisfying four layers of filtering retrieved three potential pathways: signal transduction, maintenance of plasma membrane and cell wall integrity, and nucleic acids metabolism as general mechanisms of cold stress tolerance responses involving antioxidant activity.
\end{abstract}

Keywords: anthocyanins; antioxidant activity; catalase; chilling stress; GWAS; membrane integrity; Oryza sativa L.; ROS; seedling survival; QTL

\section{Introduction}

Crop plants are constantly exposed to a broad range of abiotic factors such as extreme temperatures, high salinity, or water deficit, all of which negatively affect growth and development leading to a significant reduction in productivity [1,2]. As the world's population keeps growing, demand to increase global production of important crops such as rice, wheat, and maize must be met [3,4]. One approach to achieve this goal is to minimize crop yield losses due to environmental stressors. Therefore, it is crucial to increase the cold tolerance of a cold sensitive crop such as rice to better cope with cold temperature exposures during critical physiological stages of development [5-8].

Low-temperature conditions heavily damage the plant's ability to grow and develop by disrupting the physical and chemical compositions of the plasma membrane, protein homeostasis, and cellular metabolism [9,10]. Maintaining plasma membrane integrity is one of the vital cold stress response mechanisms in plants [11,12]. Studies have shown that a successful strategy for crop plants to deal with a chilling environment is to quickly alter the physiological characteristics of the cell membrane by changing its lipid composition [13]. This helps to ease the stress of cellular damage caused by the cold, and potentially leads to a successful recovery once the stress ends [11,13].

Various environmental stresses, such as low temperatures, when prolonged, can lead to the over-accumulation of reactive oxygen species (ROS) in crop plants such as rice, wheat, 
and maize [14,15]. These molecules are highly reactive and toxic to cellular components as they cause damage to proteins, lipids, carbohydrates, and DNA molecules [14-16]. Ultimately, this accumulation of ROS damages cell homeostasis, shatters the cellular membrane, and leads to cell death [14-16]. However, ROS also act as signaling molecules [15-17], but it is important to note that whether ROS act as damaging or signaling factors depends on the delicate equilibrium between ROS production and the plant's antioxidative ability of scavenging ROS at the proper stage of development [15,17]. Under regular growth conditions, ROS molecules are scavenged by various antioxidative defense mechanisms. In general, these mechanisms can be separated into two groups: enzymatic and non-enzymatic pathways [17].

Antioxidative defense via enzymatic pathways involves a participation of multiple enzymes, most of them members of the peroxidase family $[15,17]$. They are heme proteins, widely distributed in eukaryotes, and capable of catalyzing the turnover of hydrogen peroxide to water, rendering it harmless [17]. For example, ascorbate peroxidase (APX) uses ascorbate as an electron donor to turnover one molecule of hydrogen peroxide [18]. Likewise, glutathione peroxidase (GPX) uses two molecules of reduced glutathione to break down one molecule of hydrogen peroxide [19]. Catalase (CAT) is a special member of the peroxidase family [20]. This enzyme is encoded mainly by three out of four catalase genes in rice, whose expression levels depend on the stress intensity [21,22]. Unlike other peroxidase enzymes, CAT catalyzes the turnover of two molecules of hydrogen peroxide simultaneously to water and oxygen gas in the cell [20]. Studies in rice have been done to investigate the expression, cloning, and characterization of these CAT genes for abiotic stress tolerance [23,24]. Hence, the ability of CAT turning over hydrogen peroxide may be a proxy for studying the cell's ability to cope with ROS under low temperature conditions $[17,20,21]$.

The other antioxidative defense in plants is non-enzymatic in which plants utilize a diverse range of phenolic compounds, known as flavonoids, that are primarily derived from phenylalanine [25]. Anthocyanins and its sugar-free counterpart, anthocyanidins, are a major group of flavonoids [25]. It has been shown that low temperatures lead to anthocyanin accumulation, whereas high temperatures decrease anthocyanin content due to disruption of enzymes involved in anthocyanin biosynthesis [26]. The family of anthocyanins contains mainly six members, cyanidins, peonidins, delphinidins, malvidins, pelargonidin, and petunidin [25-27]. Cells that are rich in cyanidins have higher turnover rates of ROS, preventing them to cause oxidative damage [28,29], while more peonidins may lead to lignin synthesis, a major component of the plant cell wall [30]. Plants grown under acidic conditions tend to have higher amounts of cyanidins, peonidins, and delphinidins compared to other anthocyanins [27,31-33]. Stabilizing the anthocyanin profile with an influx of magnesium ions under low temperature conditions improves rice plant survivability and reduces grain yield loss [33,34]. Together, the plant's profile of anthocyanin, and its antioxidative activity, may also be a proxy for studying cold tolerance in plants $[28,34]$.

The major purpose of this study was to map new quantitative trait loci (QTL) and associate previously found QTL responsible for cold stress tolerance to antioxidative mechanisms in crop plants using Asian rice (O. sativa) as the model organism. Asian rice is an excellent model for this study for the following reasons. First, it is one of the most commonly cultivated cereals for grain production and feeds over half of the world's population $[1,2,11]$. Second, Asian rice is the first monocot crop plant whose genome was fully sequenced [35]. Genomics studies revealed that Asian rice has two subspecies: japonica and indica, and five major subpopulation groups [35,36]. The japonica subspecies (hereafter referred to as JAPONICA) has three major subgroups: aromatic (ARO), temperate japonica (TEJ), and tropical japonica (TRJ), as well as admixtures within the subspecies (MIXJ) [35,37]. The indica subspecies (hereafter referred to as INDICA) has two major subgroups: aus (AUS) and indica (IND), as well as admixtures within the subspecies (MIX-I) [35,37]. Additionally, there are multiple admixtures between the two subspecies (ADMIX) [35,37]. Accessions from subpopulations within the INDICA subspecies are generally more-cold 
sensitive than those from within the JAPONICA subspecies, which are in general, relatively cold tolerant [35]. Overall, single nucleotide polymorphism data for more than a thousand accessions are available for genetic mapping of candidate genes that may help improve cold stress tolerance of rice cultivars [35-37]. Third, genome-wide association study (GWAS) tools for Asian rice have been developed $[38,39]$ and shown to be successful in mapping not only candidate genes responsible for low temperature responses [40], but also for other abiotic and biotic stressors [41-44].

\section{Materials and Methods}

\subsection{Plant Materials}

Seeds of 370 O. sativa accessions from the Rice Diversity Panel 1 (RDP1) were obtained from the Genetic Stocks-Oryza (GSOR) collection located at the USDA-ARS Dale Bumpers National Rice Research Center (USDA-ARS DBNRRC; Stuttgart, AR). The 370 RDP1 accessions utilized in this study represented eight subpopulations (Figure 1): aus (53 accessions), indica (74), aromatic (11), temperate japonica (92), tropical japonica (93), admixtures of two or more indica and aus accessions (6), admixtures of two or more temperate japonica and tropical japonica accessions (30), and admixtures of one or more accessions from temperate japonica and tropical japonica with one or more accessions from the indica and aus subpopulations (11). RDP1 accessions were genotyped by McCouch et al. 2016 [38]. Based on previous told tolerance response experiments, we assigned temperate japonica and tropical japonica accessions, as well as admixtures between them to the Cold Tolerant cluster (TOL), aromatic accessions and admixtures between two subspecies to the Intermediate Cold Tolerant cluster (INT), and aus and indica accessions, as well as admixtures between them to the Cold Sensitive cluster (SEN) [40,44,45].

A)

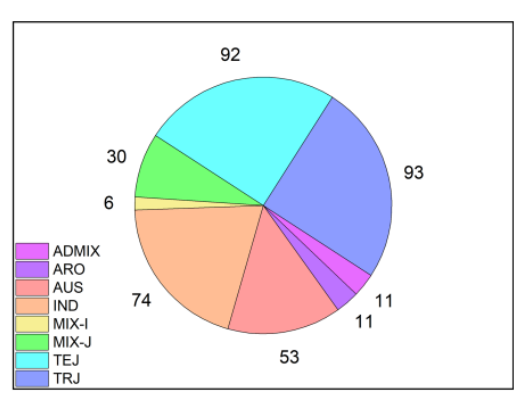

B)

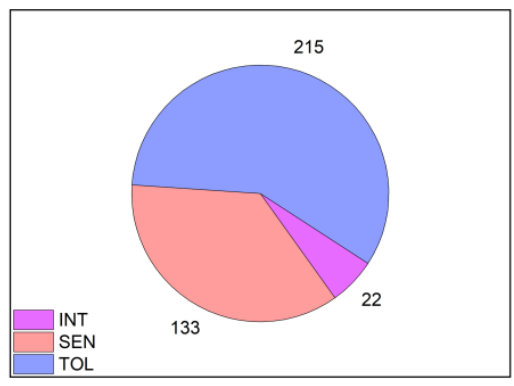

Figure 1. Pie charts of the genetic background composition of the 370 rice accessions used in this study, and the grouping of them into 3 cold tolerance clusters. (A) Subpopulation distribution of the 370 accessions. ADMIX: admixes between accessions of the two subspecies INDICA (aus and indica) and JAPONICA (aromatic, temperate japonica, and tropical japonica); ARO: aromatic; AUS: aus; IND: indica; MIX-I: admixed INDICA; MIX-J: admixed JAPONICA; TEJ: temperate japonica; TRJ: tropical japonica. (B) Grouping of the eight subpopulations into 3 cold tolerance clusters. TOL: Cold Tolerant, composed of MIX-J, TEJ, and TRJ; INT: Intermediate Cold Tolerant, composed ADMIX, and ARO; SEN: Cold Sensitive, composed of AUS, IND, and MIX-I (see Figure 2 and Table 1 for details). 
Table 1. Means and standard error for four phenotyping assays using 370 RDP1 O. sativa accessions after a 7-day-10 ${ }^{\circ} \mathrm{C}$ chilling treatment. ARO: aromatic; AUS: aus; IND: indica; MIX-I: admixed accessions within INDICA; MIX-J: admixed accessions within JAPONICA; TEJ: temperate japonica; TRJ: tropical japonica; TOL: Cold Tolerant; INT: Intermediate Cold Tolerant; SEN: Cold Sensitive.

\begin{tabular}{cccccc}
\hline Genetic Background & $\begin{array}{c}\text { Number of } \\
\text { Accessions }\end{array}$ & $\begin{array}{c}\text { Low Temperature } \\
\text { Seedling } \\
\text { Survivability (\%) }\end{array}$ & $\begin{array}{c}\text { Electrolyte } \\
\text { Leakage (\%) }\end{array}$ & $\begin{array}{c}\text { Catalase } \\
\text { Activity (AU) }\end{array}$ & $\begin{array}{c}\text { Anthocyanin } \\
\text { Activity (AU) }\end{array}$ \\
\hline ADMIX & 11 & $80.22 \pm 2.05$ & $15.74 \pm 2.02$ & $11.89 \pm 1.16$ & $15.33 \pm 1.14$ \\
ARO & 11 & $80.60 \pm 3.32$ & $19.65 \pm 2.41$ & $11.96 \pm 1.00$ & $20.47 \pm 1.45$ \\
AUS & 53 & $13.11 \pm 1.76$ & $36.43 \pm 1.70$ & $6.68 \pm 0.26$ & $10.30 \pm 0.44$ \\
$I N D$ & 74 & $27.44 \pm 1.46$ & $32.47 \pm 1.22$ & $6.77 \pm 0.27$ & $10.59 \pm 0.45$ \\
MIX-I & 6 & $14.91 \pm 4.26$ & $40.38 \pm 4.24$ & $7.41 \pm 0.89$ & $8.80 \pm 1.26$ \\
MIX-J & 30 & $94.39 \pm 1.10$ & $15.15 \pm 0.95$ & $13.45 \pm 0.68$ & $20.54 \pm 1.16$ \\
TEJ & 92 & $95.03 \pm 0.65$ & $15.66 \pm 0.63$ & $14.35 \pm 0.47$ & $22.28 \pm 0.70$ \\
TRJ & 93 & $93.89 \pm 0.74$ & $15.78 \pm 0.66$ & $13.27 \pm 0.39$ & $20.57 \pm 0.68$ \\
TOL (MIX-J+TEJ+TRJ) & 215 & $94.45 \pm 0.59$ & $15.64 \pm 0.39$ & $13.76 \pm 0.20$ & $21.30 \pm 0.36$ \\
INT (ADMIX+ARO) & 22 & $80.41 \pm 5.30$ & $17.70 \pm 0.36$ & $11.93 \pm 0.71$ & $17.90 \pm 1.28$ \\
SEN (AUS+IND+MIX-I) & 133 & $21.16 \pm 2.11$ & $34.40 \pm 1.13$ & $6.76 \pm 0.22$ & $10.39 \pm 0.29$ \\
All & 370 & $67.27 \pm 2.01$ & $22.51 \pm 0.66$ & $11.13 \pm 0.23$ & $17.17 \pm 0.36$ \\
\hline
\end{tabular}

A)

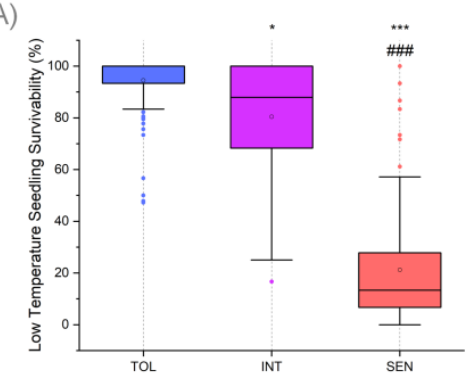

C)

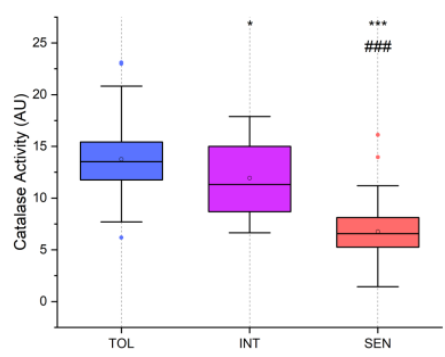

B)

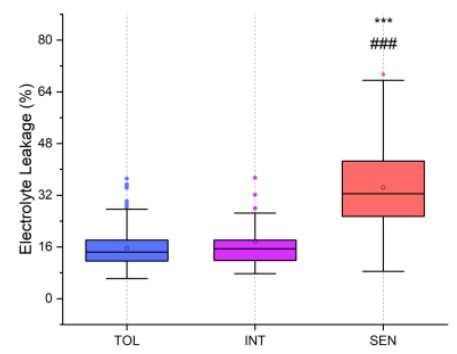

D)

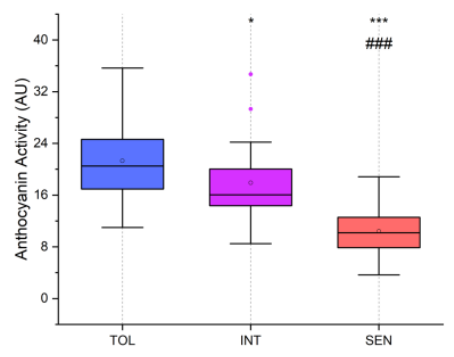

Figure 2. Box plots of mean values for four phenotypes after a 7 -day- $10{ }^{\circ} \mathrm{C}$ chilling treatment for accessions of three cold tolerance clusters (see Figure 1 for details). (A) Low Temperature Seedling Survivability (LTSS) values for rice accessions of the three cold tolerance clusters. (B) Electrolyte Leakage (EL) values measuring membrane integrity after chilling stress for rice accessions of the three cold tolerance clusters. (C) Catalase (CAT) Activity values measuring enzymatic antioxidative activity for rice accessions of the three cold tolerance clusters. (D) Anthocyanin (ANT) Activity values measuring non-enzymatic antioxidative activity for rice accessions of the three cold tolerance clusters. TOL: Cold Tolerant; INT: Intermediate Cold Tolerant; SEN: Cold Sensitive. Significant differences compared to the TOL cluster are labeled by the symbol "*". Significant differences compared to the INT cluster are labeled with the symbol "\#". ***/\#\#\#: $p<0.001 ;{ }^{*}: p<0.05$.

A smaller subset of 70 accessions was used as warm controls for catalase and anthocyanin activity assays. This subset had representative accession from all eight subpopulation groups: ADMIX (4), ARO (4), AUS (12), IND (12), MIX-I (4), MIX-J (10), TEJ (12), and TRJ (12). 


\subsection{Growth and Stress Conditions}

Seeds were germinated in distilled water at $37^{\circ} \mathrm{C}$ in the dark for $48 \mathrm{~h}$ in petri dishes with $0.1 \%$ bleach solution to prevent bacterial contamination. Germinating seeds were transferred into PCR strips after $48 \mathrm{~h}$ of germination, placed into pipette tip boxes, and grown hydroponically with deionized water only. Each accession was represented by up to 8 seedlings (one PCR strip) per box in a triplicate randomized block design, i.e., one line per strip, 12 lines per box, 3 boxes per set, 32 sets per trial (including control checks), with a total of 3 trials. Seedlings were grown under $12 \mathrm{~h}$ light (approx. $150 \mu \mathrm{E}$ photon flux) $/ 12 \mathrm{~h}$ dark and $28^{\circ} \mathrm{C}$ day $/ 25^{\circ} \mathrm{C}$ night periods. Distilled water was substituted with quarter strength Murashige-Skoog basal salt medium 10 days after germination. Two cold tolerance checks for growth conditions were cold tolerant temperate japonica accession Krasnodarskij 3352, and cold sensitive aus accession Carolino 164. The checks were grown in boxes of randomly selected sets $(4,12,16,20,28$, and 32$)$ as controls for every six sets $(1-6,7-12,13-18,19-24,25-30,31-32)$. The two control checks had no significant difference in phenotypes of interest between sets (Supplementary Figure S1).

14-day-old seedlings were transferred for 7 days to a $10{ }^{\circ} \mathrm{C}$ growth chamber with identical light-dark cycles. Watering was done once every other day to account for water depletion in boxes and to buffer temperature fluctuations. At the end of the treatment, the middle segment of each seedling was collected for the electrolyte leakage assay; other seedlings' shoot tissues were collected for catalase and anthocyanin activity assays.

The remaining stressed seedlings were moved back to regular growth conditions mentioned above for 7 days, with similar watering schedule of once every other day. Low-temperature seedling survivability was recorded after 7 days of recovery.

\subsection{Measurement of Electrolyte Leakage (EL)}

EL measurements were done as previous described, with slight modifications [11,40]. Briefly, at the end of the 7-day stress period, the middle region of the second leaf was collected from three individual seedlings and cut into four equally sized segments. The pieces were washed in distilled water (conductivity $\leq 2 \mu \mathrm{S} / \mathrm{cm}$ ), transferred into screw-cap glass tubes filled with $5 \mathrm{~mL}$ of distilled water, and shaken at $200 \mathrm{rpm}$ for $60 \mathrm{~min}$ at room temperature to release cellular electrolytes from damaged tissues. EL of each of the three replicate samples was measured by taking out $120 \mu \mathrm{L}$ of the solution and adding it into the well of a hand-held LAQUAtwin B-771 conductivity meter (Horiba Scientific, Japan). After the initial reading, leaf samples were boiled for $20 \mathrm{~min}$ to release the total cellular electrolytes. Samples were cooled to room temperature, shaken again at $200 \mathrm{rpm}$ for $30 \mathrm{~min}$, and the final electrolyte leakage reading was done. EL percentage was determined as [(initial EL) $/($ total EL) $] \times 100$.

\subsection{Measurement of Catalase Activity (CAT)}

CAT assays were done as previously described, with slight modifications [11]. Briefly, proteins from $100 \mathrm{mg}$ of finely ground cold stressed tissues (mixture of at least three plants) were extracted with $700 \mu \mathrm{L}$ of phosphate buffer (pH 7.0). Samples underwent a centrifugation at $14,000 \times g$ for $5 \mathrm{~min}$, and the supernatant was collected and diluted 1:1 with the same phosphate buffer. Total protein concentration was measured using the Bradford reagent (Fisher Scientific, Hampton, NH, USA). For the CAT activity assay, filter paper discs ( $8 \mathrm{~mm}$ diameter) were soaked for $5 \mathrm{sec}$ in 5 -fold diluted protein extracts, placed on a paper towel for another $5 \mathrm{sec}$ to get rid of excessive extracts. Discs were then immediately placed at the bottom of a $50-\mathrm{mL}$ glass beaker containing $30 \mathrm{~mL}$ of freshly made $1 \% \mathrm{H}_{2} \mathrm{O}_{2}$. CAT activity was determined as the time the disc took to reach the surface of the $\mathrm{H}_{2} \mathrm{O}_{2}$ solution ( $30 \mathrm{~mm}$ in height). CAT activity was calculated as Activity Units = [(30 mm/time in sec)/(total protein concentration in $\mathrm{mg})]$. 


\subsection{Measurement of Anthocyanin Activity (ANT)}

ANT assays were done as previously described, with slight modifications [11]. Briefly, phenolic compounds were isolated from $100 \mathrm{mg}$ of finely ground cold stressed and control tissues (mixture of at least three plants) with $700 \mu \mathrm{L}$ of 70:30:1 methanol:water:trifluoroacetic acid extraction buffer. Samples were incubated in the dark overnight at room temperature. Samples were collected after one round of centrifugation at $14,000 \times g$ for $20 \mathrm{~min}$. The supernatant was collected and filtered through a 13-mm syringe containing one layer of $0.2-\mu \mathrm{m}$ PTFE membrane. The total phenolic compound content in mg was calculated as $\left\{\left[\left(\mathrm{OD}_{520}-\mathrm{OD}_{700}\right) \times 449.2 \times 103\right] \times(1 / 26900)\right\} .25 \mu \mathrm{L}$ of this extract were mixed with $200 \mathrm{~mL}$ of $0.25 \mathrm{mM}$ 2,2-diphenyl-1-picrylhydrazyl (Sigma). The mixture was incubated with shaking at $200 \mathrm{rpm}$ for $30 \mathrm{~min}$. Absorbance at $517 \mathrm{~mm}$ was recorded. Anthocyanin activity was calculated as ANT activity $=\left\{\left[\left(\mathrm{OD}_{517}\right.\right.\right.$ of blank $-\mathrm{OD}_{517}$ of sample $) / \mathrm{OD}_{517}$ of blank] $\times 100 /$ (total phenolic compound content in $\mathrm{mg})\}$.

\subsection{Measurement of Low Temperature Seedling Survivability (LTSS)}

Low temperature seedling survivability was determined after 7 days of recovery via visual inspection, as described previously $[11,37,40]$. Specifically, alive seedlings were mostly green while dead seedlings were mostly wilted and/or bleached in the meristem region. The mean percent survivability was calculated as [(number of alive seedlings)/(number of stressed plants) $\times 100]$.

\subsection{Genome-Wide Association Study (GWAS)-Based Quantitative Trait Locus (QTL) Mapping}

The mean values of three trials from each individual phenotyping assay were averaged, and that average was used for GWAS-Based QTL mapping via the publicly available Cornell GWAS mapping pipeline [38] as described previously [40]. Briefly, this pipeline runs in conjunction with 700,000 SNPs of the High-Density Rice Array (HDRA) [38,44,45] to generate Manhattan and quantile-quantile (QQ) plots. Reference SNPs for HDRA were from the temperate japonica cultivar Nipponbare and the indica cultivar 93-11 representing the JAPONICA and INDICA subspecies, respectively [45]. The pipeline uses a variance component approach implemented in the publicly available software, efficient (linear) mixed-model association eXpedited (EMMAX), to map HDRA-derived $700 \mathrm{~K}$ SNPs to phenotype and to account for population structure by calculating and including a kinship matrix as a covariate, which helps to distinguish true associations from false positives due to relatedness between accessions. The kinship matrix was calculated using identity by state (IBS) to group identical allele states while excluding shared ancestry. Default settings for the Cornell GWAS mapping pipeline were set as minor allele frequency (MAF) $>10 \%$, minor allele count (MAC) $>1$, percent missing allele $<30 \%$, false discovery rate $=0.1$, and best SNP limit $=0.05$.

\subsection{QTL Mapping}

Manhattan plots from GWAS runs were extracted as Excel files and -log10( $p$-value) values were calculated for each SNP. QTL were assigned to genomic regions with at least 3 significant SNPs within a $1 \mathrm{Mb}$ segment. Significant SNPs had the -log10(expect) value of 3.0, corresponding to - $\log 10$ ( $p$-value) of 4.3,3.6, and 2.8 for LTSS, EL, and CAT and ANT activities, respectively, based on generated QQ plots (Supplementary Figure S2).

\subsection{Gene Identification and Gene Ontology (GO) Term Analysis}

Genes within selected QTL were found via Allele Finder with the following settings [38]: "Dataset" = "HDR6.4_RDP1-RDP2-NIAS-sativa-only", and "Rice sub populations for query" = "admixed", "admixed-indica", "admixed-japonica", "aromatic", "aus", "indica", "temperate-japonica", "tropical-japonica". GO terms for these genes were retrieved via PhytoMine with gene names in MSU format and "Oryza sativa v7.0" selected as the the "Organism". Table GO term enrichment was done with the GO Term Enrichment tool from PlantRegMap, with "Oryza sativa subsp. japonica" selected for "Species", and 
" $\leq 0.05$ " for " $p$-value". GO term clustering and visualization were done via MonaGO (https:/ / monago.erc.monash.edu/, 21 August 2021) with GO IDs and their associated $p$-values and "number of overlapping genes" selected for the "Distance Measurement". All genes used in this analysis were present in Nipponbare (temperate japonica) and 93-11 (indica), both of which were used as reference genomes for the High-Density Rice Array [45].

\subsection{Correlation Analysis and Statistical Analysis}

Correlation analyses between phenotypes were done using the OriginLab Pro 2018 SR1 b9.5.1.195 program (OriginLab Corp., Northampton, MA, USA). Linear, Boltzmann, and exponential decay correlations were calculated, and best-fitting options selected. Significant differences for all cold tolerance phenotypes between the three clusters were calculated using OriginLab Pro 2018 SR1 b9.5.1.195 with unpaired Student's $t$-test option selected with an addition of Welch's test selected as necessary since the populations between the three clusters were not equal and had to be calculated accordingly.

\section{Results}

\subsection{Summary of Low Temperature Seedling Survivability (LTSS) Results}

To correlate enzymatic and non-enzymatic antioxidative activities during chilling stress with general seedling survivability, two-week old seedlings were exposed for one week to continuous chilling stress of $10^{\circ} \mathrm{C}$. After one week of recovery at regular growth condition, seedlings that were green and healthy were counted as successfully recovered while those that were white and/or wilted were counted as dead. For statistical analysis, Rice Diversity Panel 1 (RDP1) accessions were assigned to three clusters based on their genetic background (see Materials and Methods). This classification was further supported by a high degree of consistency between LTSS (and electrolyte leakage) results reported by Shimoyama et al. 2020 [40] and results shown here using the same RDP1 accessions (Supplementary Figure S3). The mean LTSS score for the Tolerant cluster was 94.5\%; for the Intermediate cluster, $80.4 \%$; and for the Sensitive cluster, 21.2\% (Table 1; Figure 2A). Compared to the Tolerant cluster, LTSS scores for the Intermediate and Sensitive clusters were significantly lower, with $p$-values (Student's $t$-test) of $1.53 \times 10^{-02}$ and $3.52 \times 10^{-72}$, respectively. Compared to the Intermediate cluster, LTSS scores for the Sensitive cluster were significantly lower, with a $p$-value (Student's $t$-test) of $4.04 \times 10^{-11}$. The variances were similar and consistent between the three experiments (Supplementary Table S1). Since the Tolerant cluster made up approx. $60 \%$ of the rice collection used in this study, we expected LTSS scores for the population to be skewed toward the high end. As shown in Supplementary Figure S4a, 41 accessions had LTSS scores in the range of 80-90\%, and 187 accessions had LTSS scores in the range of $90-100 \%$, while the mean LTSS score for all 370 accessions was $67.3 \%$. Thus, as expected, $61.6 \%$ of the accessions had LTSS scores at the higher end, between $80-100 \%$. All three experiments produced a similar distribution profile (Supplementary Figure S5A-C).

\subsection{Summary of Electrolyte Leakage (EL) Results}

To correlate enzymatic and non-enzymatic antioxidative activities during chilling stress with membrane damage sustained during cold temperature exposure, EL in leaves was determined immediately after the 7 -day- $10{ }^{\circ} \mathrm{C}$ chilling treatment. For consistency, the middle portion of the second leaf of young seedlings was used for the EL measurements. The mean percent EL for the Tolerant cluster was $15.7 \%$; for the Intermediate cluster, $17.7 \%$; and for the Sensitive cluster, 34.4\% (Table 1; Figure 2B). Compared to the Tolerant cluster, EL scores for the Sensitive clusters were significantly higher, with $p$-values (Student's $t$-test) of $1.39 \times 10^{-34}$, respectively. Compared to the Intermediate cluster, EL scores for the Sensitive cluster were significantly higher, with a $p$-value (Student's $t$-test) of $1.81 \times 10^{-10}$. The variances were similar and consistent between the three experiments (Supplementary Table S1). Since the Tolerant cluster made up approx. $60 \%$ of the rice collection used in this study, we expected EL scores for the population to be skewed toward the low end. As 
shown in Supplementary Figure S4b, 131 accessions had EL scores in the range of 5-15\%, and 113 accessions had EL scores in the range of 15-25\%, while the mean EL score for all 370 accessions was $22.5 \%$. All three experiments produced a similar distribution profile (Supplementary Figure S5D-F).

\subsection{Summary of Catalase (CAT) Activity Results}

Immediately after the 7 -day- $10^{\circ} \mathrm{C}$ chilling treatment, whole seedling tissues, including shoots and roots, were collected to determine the antioxidative activity of CAT, a member of the enzymatic pathway for turning over reactive oxygen species (ROS). The mean CAT Activity Units (AU) for the Tolerant cluster was 13.8 AU; for the Intermediate cluster, 11.9 AU; and for the Sensitive cluster, $6.8 \mathrm{AU}$ (Table 1; Figure 2C). The variances were similar and consistent between the three experiments (Supplementary Table S1). Compared to the Tolerant cluster, CAT AUs for the Intermediate and Sensitive clusters were significantly lower, with $p$-values (Student's $t$-test) of $2.05 \times 10^{-02}$ and $1.31 \times 10^{-71}$, respectively. Compared to the Intermediate cluster, CAT AUs for the Sensitive cluster were significantly lower, with a $p$-value (Student's $t$-test) of $2.74 \times 10^{-07}$. As shown in Supplementary Figure S4c and Supplementary Figure S6a-c, compared to LTSS and EL, CAT activity scores for the 370 RDP1 accessions had a normal distribution. CAT activities for 70 accessions representing the three tolerance clusters were similar between the three clusters under warm control conditions (Supplementary Figure S7a).

\subsection{Summary of Anthocyanin (ANT) Activity Results}

Immediately after the 7 -day- $10^{\circ} \mathrm{C}$ chilling treatment, whole seedling tissues, including shoots and roots, were collected to determine the antioxidative activity of ANTs, members of the non-enzymatic pathway for turning over ROS. The mean ANT Activity Units for the Tolerant cluster was 21.3 AU; for the Intermediate cluster, 17.9 AU; and for the Sensitive cluster, 10.4 AU (Table 1; Figure 2D). The variances were similar and consistent between the three experiments (Supplementary Table S1). Compared to the Tolerant cluster, ANT AUs for the Intermediate and Sensitive clusters were significantly lower, with $p$-values (Student's $t$-test) of $1.74 \times 10^{-02}$ and $2.62 \times 10^{-74}$, respectively. Compared to the Intermediate cluster, ANT AUs for the Sensitive cluster were significantly lower, with a $p$-value (Student's $t$-test) of $7.99 \times 10^{-06}$. As shown in Supplementary Figure S4d and Supplementary Figure S6d-f, compared to LTSS and EL, ANT activity scores for the 370 RDP1 accessions had a normal distribution. ANT activities for 70 accessions representing the three tolerance clusters were similar between the three clusters under warm control conditions (Supplementary Figure S7b).

\subsection{Correlations between LTSS, EL, CAT Activity, and ANT Activity after Low Temperature Treatment}

\subsubsection{Correlation between EL and LTSS}

As LTSS scores were determined after a 7-day recovery period while EL measurements were done immediately after the chilling treatment, it was important to investigate how well EL and LTSS correlate to determine whether EL could be used to predict how well rice plant can recover after the $10^{\circ} \mathrm{C}$ chilling stress treatment. Interestingly, there was a non-linear Boltzmann type negative correlation between the two phenotypes $\left(R^{2}=0.606\right)$ (Figure 3A). The Boltzmann sigmoidal curve determined the $x$-value responsible for the 50\% LTSS threshold to be $25.8 \%$ EL. There were 211 accessions (57\%) with EL scores below this threshold that achieved at least $80 \%$ seedling survivability. 
A)

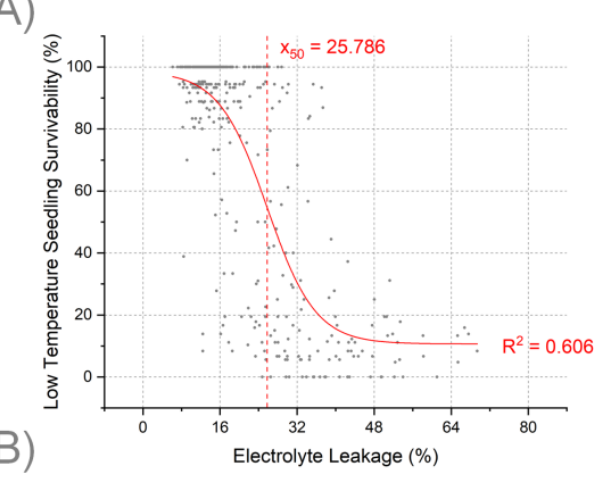

B)
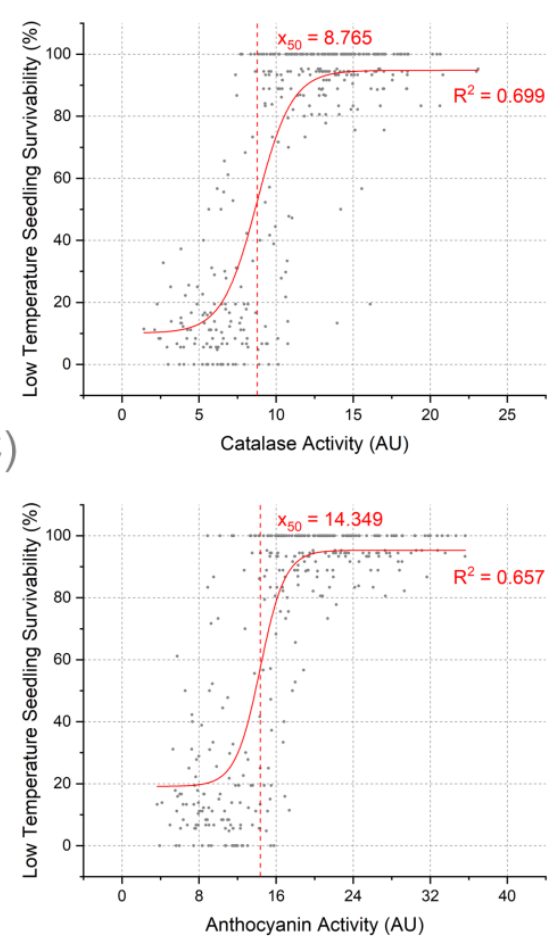

D)

E)

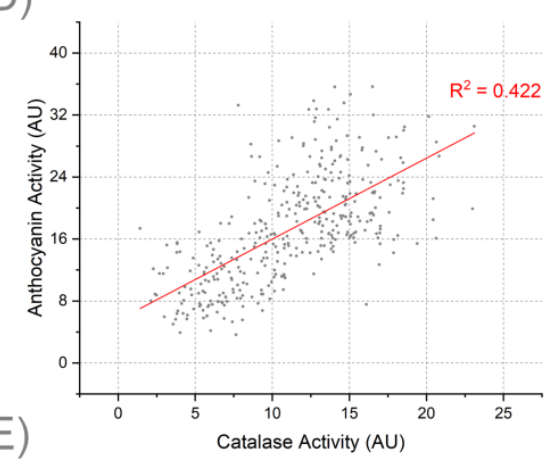

F)
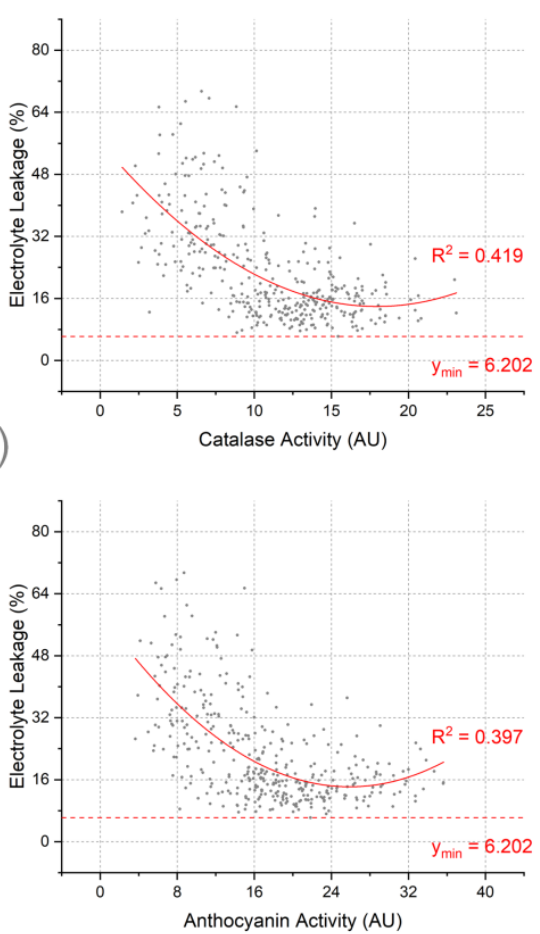

Figure 3. Correlation analyses of four chilling tolerance phenotypes after a 7-day- $10{ }^{\circ} \mathrm{C}$ treatment. Each dot shows the correlation for one accession. (A-C) Correlations between LTSS and EL, CAT, and ANT, respectively. A Boltzmann Sigmoid fit is shown based on best-fit model calculations. $X_{50}$ and the line $y=X_{50}$ show values at which EL, CAT, ANT are halfway between high LTSS and low LTSS. (D) Correlations between CAT and ANT activities. A linear fit is shown based on best-fit model calculations. (E,F) Correlations between EL, and CAT and ANT, respectively. An Exponential Decay fit is shown based on best-fit model calculations. The line $x=y_{\min }$ shows the lowest EL value after reaching the plateau for the curve.

\subsubsection{Correlation between CAT Activity and LTSS}

As CAT activity assays were done at the end of the cold exposure and LTSS scores determined one week later, a correlation analysis between CAT activity and LTSS was done to determine how well catalase activity could predict seedling survivability. There was a Boltzmann type positive correlation between CAT activity immediately after the $10{ }^{\circ} \mathrm{C}$ chilling stress and the ability of seedlings to recover one week later $\left(R^{2}=0.699\right)$ (Figure 3B). The Boltzmann sigmoidal curve determined the $\mathrm{x}$-value responsible for the $50 \%$ LTSS threshold to be 8.77 AU of CAT activity. There were 219 accessions (59\%) with CAT activities above the $8.77 \mathrm{AU}$ threshold that successfully achieved at least $80 \%$ seedling survivability. 


\subsubsection{Correlation between ANT Activity and LTSS}

Similarly, as ANT activity assays were done at the end of the cold exposure and LTSS scores determined one week later, a correlation analysis between ANT activity and LTSS scores was done to determine how well anthocyanin activity could predict seedling survivability. This showed that, similar to the CAT activity-LTSS correlation, there was a Boltzmann type positive correlation between ANT activity immediately after the $10^{\circ} \mathrm{C}$ chilling stress and the ability of seedlings to recover one week later $\left(R^{2}=0.657\right)$ (Figure 3C). The Boltzmann sigmoidal curve determined the $x$-value responsible for the $50 \%$ LTSS threshold to be 14.35 AU of ANT activity. There were 209 accessions (56.5\%) with anthocyanin activities above the $14.35 \mathrm{AU}$ threshold that successfully achieved at least $80 \%$ seedling survivability.

\subsubsection{Correlation between EL and CAT Activity}

As both CAT activity assays and EL measurements were done at the end of the cold exposure, a correlation analysis between CAT activity and EL was done to determine how well catalase antioxidative activity could predict the degree of membrane damage sustained during the cold stress period. There was an exponential decay correlation between CAT activity and cell membrane damage immediately after the $10^{\circ} \mathrm{C}$ chilling stress $\left(R^{2}=0.419\right.$; Figure 3E), that is, the higher CAT AUs, the lower EL scores. The low EL plateau (yminimum line in Figure 3E) reached by most RDP1 accessions with the highest CAT AUs was at $6.6 \%$, which is similar to the baseline EL level of undamaged rice leaves grown under warm control conditions.

\subsubsection{Correlation between ANT Activity and EL}

Likewise, both ANT activity assays and EL measurements were done at the end of the cold exposure, a correlation analysis between ANT activity and EL was done to determine how well non-enzymatic anthocyanin antioxidative activity could predict the degree of membrane damage sustained during the cold stress period. This showed that, similar to the CAT activity-EL correlation, there was an exponential decay correlation between ANT activity and plasma membrane damage sustained immediately after the $10{ }^{\circ} \mathrm{C}$ chilling stress period $\left(R^{2}=0.397\right)$ (Figure 3F). Again, the baseline low EL plateau (y-minimum line in Figure 3F) reached by most RDP1 accessions with the highest ANT AUs was at $6.6 \%$.

\subsubsection{Correlation between CAT Activity and ANT Activity}

As CAT and ANT activity assays were done to measure seedling's antioxidative ability, a correlation analysis between CAT activity and ANT activity was done to determine whether enzymatic and non-enzymatic pathways were aligned to cope with cold temperature stress. The analysis showed that there was a positive linear correlation between CAT and ANT activity immediately after the $10{ }^{\circ} \mathrm{C}$ chilling stress $\left(R^{2}=0.422\right)$ (Figure 3D).

\subsection{Genome-Wide Association Study (GWAS)-Based Mapping of Four Phenotypes}

To identify single nucleotide polymorphisms (SNPs) associated with the four phenotypes LTSS, EL, CAT activity, and ANT activity, phenotypic data for the 370 RDP1 accessions were run through the Cornell GWAS mapping pipeline [38]. At the -log10(expect) value of 3.0, the cutoff $p$-value for significant SNPs for the four phenotypes were determined to be 4.3 for LTSS, 3.6 for EL, and 2.8 for both CAT activity and ANT activity (Supplementary Figure S2). Quantitative trait loci (QTL) were identified as a region containing $\geq 3$ SNPs within a one-million-base-pair region. This yielded 25 individual LTSS, 30 EL, 31 CAT activity, and 34 ANT activity QTL (Supplementary Table S2). Of these, 22 QTL overlapped with two phenotypes and 3 QTL overlapped with three phenotypes, and 20 QTL overlapped with at least one of the antioxidant activity QTL. Since the major goal of this study was to assess the contribution of antioxidant activity to membrane integrity and seedling survivability during chilling stress, we assigned Multiple-Phenotype (MP) QTL to regions that had at least one antioxidant activity QTL overlapping with other cold stress response 
QTL (Table 2; Figure 4). The 20 qMP overlapping with at least one antioxidant activity QTL are shown in Figure 4 while a list of all individual QTL is shown in Supplementary Table S2. The most significant MP QTL was $q M P 10-2$ at $13.8-14.0 \mathrm{Mb}$ on chromosome 10 , with a LOD score of 6.80 (Table 2).

Table 2. Summary of 20 Multiple-Phenotype (MP) QTL identified by GWAS mapping for four phenotyping assays of 370 RDP1 O. sativa accessions after a 7-day- $10^{\circ} \mathrm{C}$ chilling treatment. LTSS: Low Temperature Seedling Survivability; EL: Electrolyte Leakage; CAT: Catalase Activity; ANT: Anthocyanin Activity; LOD: Logarithm of the Odds; SNP: Single Nucleotide Polymorphism. See Supplementary Table S3 for details on published QTL.

\begin{tabular}{|c|c|c|c|c|c|c|c|}
\hline QTL & Chr & Start & End & Phenotypes & Peak LOD Score & Peak SNP Gene & Published QTL \\
\hline$q M P 1-1$ & 1 & 8815194 & 9418864 & CAT, LTSS & 5.31 & - & qMT1-1 [40] \\
\hline$q M P 1-2$ & 1 & 18792455 & 18916961 & $\begin{array}{l}\text { ANT, CAT, } \\
\text { LTSS }\end{array}$ & 4.96 & LOC_Os01g34430 & $\begin{array}{l}\text { qMT1-4 [40], } \\
\text { qCTS1-2 [47] }\end{array}$ \\
\hline$q M P 1-3$ & 1 & 22290853 & 22489300 & CAT, EL & 4.27 & LOC_Os01g38740 & - \\
\hline$q M P 1-4$ & 1 & 37834095 & 37862889 & CAT, EL & 5.00 & - & qCTS1-4 [47] \\
\hline qMP3-1 & 3 & 10104198 & 10284651 & ANT, LTSS & 5.46 & - & $q L V G 3[46]$ \\
\hline$q M P 4-1$ & 4 & 2699247 & 2729293 & CAT, EL & 3.44 & LOC_Os04g05420 & qCTS4-1 [47] \\
\hline$q M P 4-2$ & 4 & 4150962 & 4265645 & ANT, EL & 4.35 & - & $\begin{array}{l}q C T S 4-1 \text { [47] } \\
q M T 4-3 \text { [40], }\end{array}$ \\
\hline$q M P 4-3$ & 4 & 32076622 & 32401404 & CAT, LTSS & 6.19 & - & $\begin{array}{c}\text { qLTSS4-3 [37], } \\
\text { qLTG4 [46] }\end{array}$ \\
\hline$q M P 5-1$ & 5 & 3512674 & 4377698 & ANT, CAT & 3.45 & - & $\begin{array}{l}\text { qLTG5-1 [46], } \\
\text { qCTS5-1 [47] } \\
\text { qMT5-3 [40], }\end{array}$ \\
\hline$q M P 5-2$ & 5 & 23154623 & 23564490 & CAT, EL & 6.08 & - & $\begin{array}{l}\text { qCTSS-5 [46], } \\
q \text { CTS5-4 [47] }\end{array}$ \\
\hline$q M P 8-1$ & 8 & 3078138 & 3346129 & ANT, CAT & 4.21 & - & $\begin{array}{c}\text { qMT8-1 [40], } \\
\text { qLTSS8-1 [37] } \\
\text { qMT8-3 [40], }\end{array}$ \\
\hline$q M P 8-2$ & 8 & 21298422 & 21317944 & ANT, LTSS & 3.45 & LOC_Os08g34030 & $\begin{array}{c}\text { qLTSS8-2 [37], } \\
\text { COLD2 [46], } \\
\text { qCTS8-4 [47] }\end{array}$ \\
\hline$q M P 8-3$ & 8 & 25620369 & 25655572 & ANT, LTSS & 6.22 & - & qMT8-4 [40] \\
\hline$q M P 10-1$ & 10 & 11675173 & 12345517 & ANT, CAT & 3.18 & - & $\begin{array}{c}\text { qLTSS10-2 [37], } \\
\text { qCTSS-10 [46] }\end{array}$ \\
\hline$q M P 10-2$ & 10 & 13841307 & 14025821 & ANT, LTSS & 6.80 & LOC_Os10g26550 & $\begin{array}{l}\text { qMT10-4 [40], } \\
\text { qCTSS-10 [46] }\end{array}$ \\
\hline$q M P 11-1$ & 11 & 2685973 & 2766157 & $\begin{array}{c}\text { CAT, EL, } \\
\text { LTSS }\end{array}$ & 6.43 & - & - \\
\hline$q M P 11-2$ & 11 & 28342262 & 28475216 & ANT, EL & 3.53 & - & $q M T 11-3$ [40] \\
\hline$q M P 12-1$ & 12 & 2192895 & 2390059 & ANT, LTSS & 6.47 & - & $q M T 12$ [40] \\
\hline$q M P 12-2$ & 12 & 8027010 & 8406160 & CAT, EL & 5.26 & LOC_Os12g14680 & qCTSS-12 [46] \\
\hline$q M P 12-3$ & 12 & 9435619 & 9819447 & CAT, EL & 4.14 & - & qCTSS-12 [46] \\
\hline
\end{tabular}




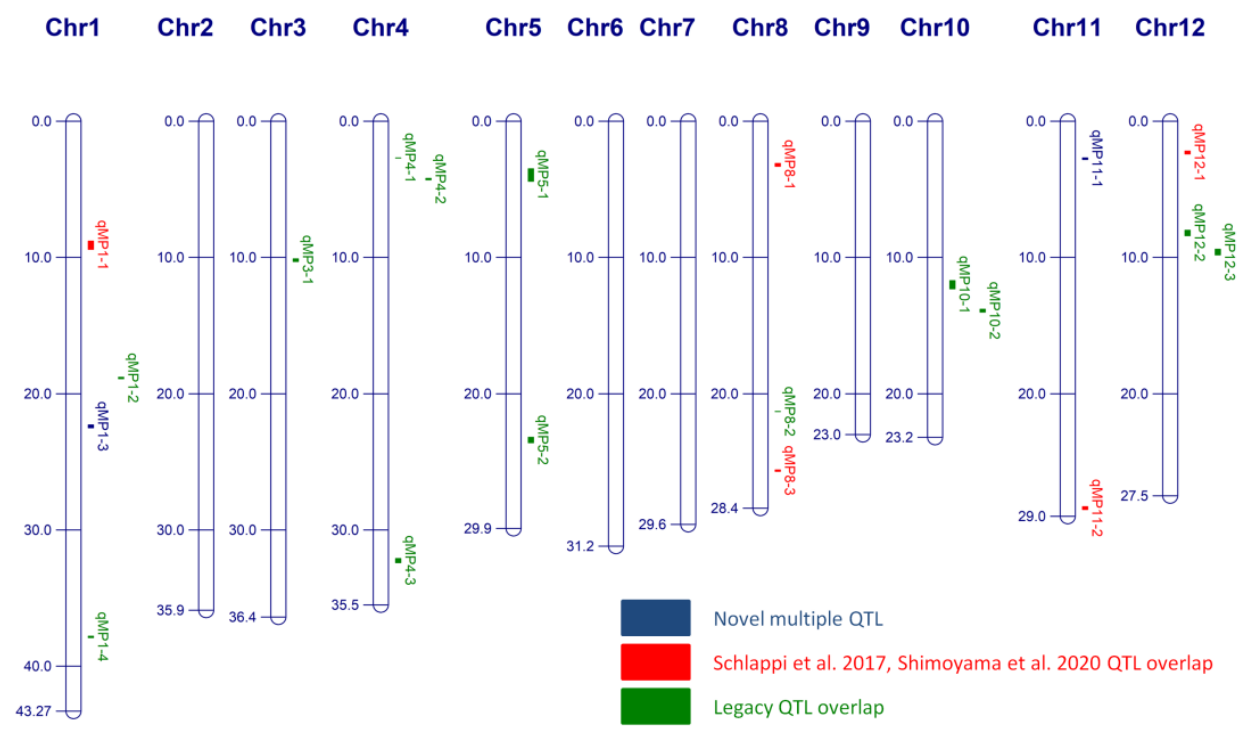

Figure 4. Genomic locations of 20 Multiple-Phenotype (MP) QTL. Numbers along the chromosomes (Chr) are million-basepair (Mbp) units. Boxes show regions containing at least one antioxidant QTL ( $q C A T ; q A N T)$ overlapping with another QTL ( $q L T S S ; q E L ; q C A T$; or $q A N T$ ). Blue boxes show regions of novel cold stress tolerance QTL identified in this study; red boxes show regions of $q M P S$ overlapping with cold stress tolerance QTL reported in Schläppi et al. 2017 [37] and Shimoyama et al. 2020 [40]; green boxes show $q M P S$ overlapping with some legacy seedling stage cold stress tolerance QTL reported in the last five years (Lv et al. 2016 [46], and Wang et al. 2016 [47]).

\subsection{GO Term Analyses of Annotated Genes within Multiple-Phenotype QTL}

The chromosomal regions spanning those $20 \mathrm{MP}$ QTL contained 579 annotated genes. However, 161 of them were annotated as either transposons, retrotransposons, expressed proteins, or hypothetical protein coding genes. These genes were not used for GO term analysis and enrichment, leaving 418 genes for these analyses. For the GO term analysis, there were 94 terms for the Biological Process run, 56 terms for the Molecular Function run, and 14 terms for the Cellular Component run with $p$ values $\leq 0.05$. These GO terms were further enriched using a $p$ value cutoff of 0.001 . This cutoff enriched $20 \mathrm{GO}$ terms for Biological Process; 19 GO terms for Molecular Function; and nine GO terms for Cellular Component (Figure 5).

For Biological Process, 17 GO terms were selected after accounting for similarities. From these, there were four distinct clusters shared by at least half of the contributing genes. The first cluster was for "cell recognition" and "cell communication". The second cluster was for "pollination" and "reproductive process". The third cluster was for "response to stress", "response to stimulus", and "defense response". And the fourth cluster was "carbohydrate phosphorylation", "pectin biosynthetic process", and "xylan biosynthetic process". Within the first cluster, the terms "cellular protein modification process" and "oligo peptide transport" were the most significant (Figure 5).

For Molecular Function, 17 GO terms were selected after accounting for similarities. From these, there were three distinct clusters shared by at least half of the contributing genes. The first cluster was for "nucleotide binding", "ribonucleotide binding", "nucleoside binding", "anion binding", and "calcium ion binding". The second cluster was for "catalytic activity", "protein kinase activity", "protein serine/threonine kinase activity", and "GTP diphosphokinase activity". And the third cluster was for "transferase activity", "phosphotransferase activity", "6-phosphofructose-2-kinase activity", "xylan-Oacetyltransferase activity". Within the first cluster, the terms "Ras GTPase binding" and "transporter activity" were the most significant (Figure 5).

For Cellular Component GO terms, of the nine enriched GO terms, one distinct cluster was shared by at least half of the contributing genes. This cluster was for "chromosome", 
"replisome", "replication fork", and "nuclear lumen". Within this cluster, the terms "cytosol" and "plasmodesma" were the most significant (Figure 5).

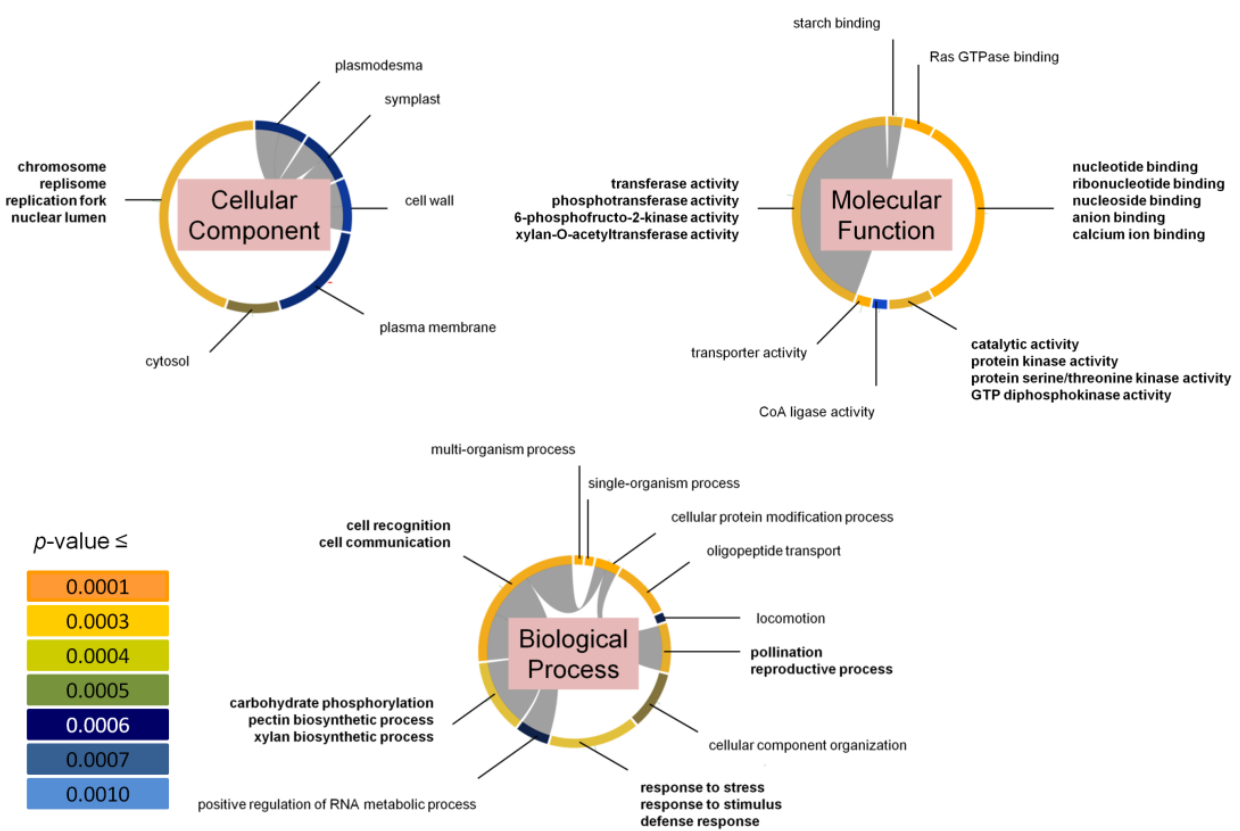

Figure 5. Gene Ontology (GO) term enrichment of annotated genes found in regions of the 20 Multiple-Phenotype QTL shown in Figure 4. The segment color corresponds to different $p$ values (as shown). The segment length corresponds to the number of genes contributing to that GO term/cluster. In Bold: multiple GO terms clustered together based on overlapping genes.

\section{Discussion}

\subsection{Cold Stress Tolerance Scores of Rice Accessions Cluster with Their Respective Subgroups}

The purpose of this study was to correlate four cold stress tolerance responses of 370 Rice Diversity 1 (RDP1) accessions with each other to further our understanding of biochemical and genetic response mechanisms involved in establishing cold tolerance in rice. We moreover wanted to identify robust parameters immediately after the cold temperature stress exposure to predict the overall low-temperature seedling survivability (LTSS) after one week of recovery. To this end, we assessed at the end of the cold stress period percent electrolyte leakage (EL) as a measure of the degree of membrane damage sustained during that period, and catalase (CAT) and anthocyanin (ANT) activities as a measure of enzymatic and non-enzymatic antioxidant activities, respectively, to detoxify reactive oxygen species (ROS) produced during the cold stress period. A distribution analysis of the scores for all four low-temperature stress phenotypes indicated that the 370 RDP1 accessions generally cluster with the genetic backgrounds of their subgroups. This means that accessions from the temperate japonica and tropical japonica subgroups, and admixes between the two subgroups, classified as the JAPONICA subspecies of rice, can be assigned to the cold Tolerant cluster, because they generally had low EL (i.e., low membrane damage), high CAT and ANT (i.e., high ROS detoxification) activities, and overall high LTSS (Table 1; Figure 2). In contrast, accessions from the aus and indica subgroups, and admixes between the two subgroups, classified as the INDICA subspecies of rice, can be assigned to the cold Sensitive cluster, because they generally had high EL (i.e., high membrane damage), low CAT and ANT (i.e., low ROS detoxification) activities, and overall low LTSS (Table 1; Figure 2). Accessions from the aromatic subgroup and admixes between subgroups of the INDICA and JAPONICA subspecies can be assigned to the Intermediate cold tolerant cluster, because the means of their phenotypic scores ranged between those of the Tolerant and the Sensitive clusters (Table 1; Figure 2). This finding is consistent 
with previous publications showing that accessions from the JAPONICA subspecies are generally more-cold tolerant than accessions from the INDICA subspecies, which is a good prerequisite for mapping genomic regions containing genes involved in cold tolerance responses [11,40].

Although previous publications suggested a linear correlation between EL and LTSS after cold stress exposure [40,48], our results suggest a sigmoidal relationship between those two parameters (Figure 3). Under conditions tested here, there was a threshold value of $25.8 \%$ EL below which LTSS scores were high in a relative non-linear fashion and above which LTSS scores were low. However, as previously reported [40,48], some rice accessions had low EL and low LTSS or high EL and high LTSS scores, suggesting that besides membrane damage, other molecular and physiological events determine seedling survivability during the one-week recovery period. Consistent with our EL data, correlations between CAT and ANT antioxidant activities and LTSS also followed a sigmoid relationship (Figure 3). Above the thresholds of 8.8 AU for CAT and 14.4 AU for ANT, LTSS scores were high and did not increase much at higher AU values while below those values, LTSS scores were low and did not decrease much at lower AU values. Interestingly, a distribution analysis of percent EL and LTSS showed that the values were skewed toward one end or another, while antioxidative activities followed a normal distribution (Supplementary Figure S4).

It is worth noting that within the Tolerant cluster, most of the temperate japonica accessions had high antioxidative activity and low membrane damage, while within the Sensitive cluster, most aus accessions had low antioxidative activity and high membrane damage. Meanwhile, within these two clusters, accessions from the tropical japonica and indica subgroups had a wider distribution of their antioxidative activity and membrane damage scores. One explanation for this is that because low-temperature tolerance in plants is a complex trait $[8,11,37,40]$, every molecular/genetic pathway involved needs to be fine-tuned to perfection $[8-10,49,50]$. As low temperatures negatively affect plants in multiple ways, including nutrient uptake, resources within plants might become scarce and trade-offs need to be made $[9,10]$. Therefore, it might be too "expensive" for some plants to keep increasing antioxidative activities to fully reduce ROS to pre-stress levels. Our results showed that some rice accessions with high LTSS values had antioxidative activity scores barely above the measured threshold levels. Likewise, some accessions had EL scores close to the threshold level yet were still able to successfully recover with high LTSS values. This would explain observations showing that in indica accessions, some defense and abiotic stress tolerance genes are upregulated only when intracellular ROS abundance reaches a certain level [51]. It is possible that similarly, certain cold tolerance genes are only upregulated when the cell membrane suffers an adequate degree of damage. This would explain why many tropical japonica and some indica accessions with good LTSS scores can tolerate relatively high membrane damage and low antioxidant activity levels, because these conditions might activate stress response genes fixing damaged membranes during recovery growth. Meanwhile, temperate japonica accessions with low membrane damage can afford high antioxidative activities to detoxify ROS and achieve high LTSS. Additionally, multiple transcriptomic studies have shown that cold stress responsive genes are regulated differently depending on the stress intensity [52-56]. Taken together, different rice accessions might balance different cold stress tolerance response strategies with the requirement for growth and development during the recovery period.

\subsection{Genome-Wide Association Study (GWAS)-Based Mapping of Four Cold Tolerance Traits}

Based on our previous experience with the GWAS pipeline used in this study, we are confident that the 20 QTL associated with two or three overlapping cold tolerance traits are robust indicators not only for genes regulating membrane integrity and overall seedling survival after cold stress exposure in rice, but also for genes that control antioxidative activity to counteract ROS production during stress exposure. Of these 20 QTL, 18 overlapped with previously mapped QTL associated with various cold tolerance traits 
(Figure 4), while 10 overlapped with previously mapped multiple-trait QTL using a similar subset of 354 RDP1 accessions [40]. 14 QTL overlapped with previous mapping studies using different rice populations $[37,40,46,47]$ (Table 2), whereas the two QTL $q M P 1-3$ and qMP11-1 at $22 \mathrm{Mb}$ on chromosome 1 and $2 \mathrm{Mb}$ on chromosome 11, respectively, appear to be novel cold tolerance QTL. Because the 20 QTL found in this study span regions of less than $1 \mathrm{Mb}$, they will help narrow down cold tolerance candidate genes of previously mapped QTL to smaller segments.

Several genes within some of the 20 QTL were previously shown to contribute to cold tolerance in rice $[57,58]$. For instance, upregulation of OsCTB4A located within qMP4-1 increased ATP synthase activity and ATP content, enhanced seed setting, and improved yield under cold stress conditions [59]. OsFBK15, one of the major factors affecting cold tolerance in rice at the booting stage, is closely linked to $q M P 4-3[60,61]$. OsRH42 is found within $q M P 8-1$ and was previously shown to be antagonistic for premRNA splicing in plant under chilling stress [62]. The MAP kinase encoding gene OsMPK5 is found within $q M P 3-1$ and was shown to be one of the regulators of gene expression and antioxidants under different stress conditions, including drought, cold and high salinity [63-66]. The MYB transcription factor encoding gene OsMYB3R-2 was found to enhance low temperature tolerance via alteration of the cell cycle and is closely linked to $q M P 1-4$ [67-69]. Overexpression of OsLAC13 was previously shown to induce hydrogen peroxide production and mitochondrial damage [70] and is linked to qMP5-2, a QTL associated with EL and CAT activity traits. The gibberellins-2-oxidase encoding gene OsGA2OX1 is within $q M P 5-1$ and was previously shown to coordinate chilling tolerance and growth in rice [71].

Interestingly, none of the multiple or single phenotype QTL we identified mapped to any of the four catalase genes in rice, which are found at $0.8 \mathrm{Mb}$ on chromosome (chr.) 2 (OsCATA), at $30.9 \mathrm{Mb}$ on chr. 6 (OsCATB), at $1.7 \mathrm{Mb}$ on chr. 3 (OsCATC), and at $23.7 \mathrm{Mb}$ on chr. 4 (OsCATD) [21], despite the fact that CAT activity was one of the phenotypes used for mapping. This can be explained with a lack of polymorphism associated with CAT genes, or with significant polymorphism associated with genes regulating CAT activity. However, there are three peroxidase genes associated with qMP1-1, LOC_Os01g15810, LOC_Os01g15830, LOC_Os01g16450, and one gene, LOC_Os05g06970, with qMP5-1. The gene LOC_Os01g15830 is also known as OsPOX1 and has been shown to be a coldresponsive gene in rice [72]. As catalases are members of the broader peroxidase family [20], it is reasonable that CAT activity QTL can be associated with peroxidase genes. Additionally, since QTL mapping was also done using the ANT activity trait, four anthocyanin reductase genes, LOC_Os04g53830, LOC_Os04g53850, LOC_Os04g53860, and LOC_Os04g53920 were found to be associated with $q M P 4-3$, and the 1 flavone-methyltransferase gene, LOC_Os08g06100, with $q M P 8$-1. As flavones, anthocyanins, and its sugar-free counterpart, anthocyanidins, work together in the non-enzymatic pathway of ROS turnover [25], it is reasonable that these genes are associated with ANT and/or CAT QTL.

\subsection{Gene Ontology (GO) Term Analysis of Genes Found in 20 Multiple-Phenotype QTL}

The GO term enrichment and clustering data of genes within multi-phenotype QTL revealed three major pathways that can influence the plant's antioxidative activity, and its overall survivability during and after cold stress exposure.

The first pathway appears to involve signal transduction between cells, because the cluster "cell recognition" / "cell communication", and the two GO terms "plasmodesma" and "symplast" were filtered out (Figure 5). Because plants are sessile and need to adapt to environmental challenges, complex signaling cascades need to be adjusted accordingly $[8,11,49]$. Studies have shown that for the plant to utilize ROS as signaling agents, CAT activity is often dowregulated early during stress exposure [73,74]. However, as the stress prolongs, ROS must be turned over due to their destructive nature towards cellular components [14-16]. Hence, it makes sense that from mapping cold tolerance 
candidate genes via antioxidative activity, a complex network for signaling between cells is revealed.

The second pathway appears to involve maintenance of the plasma membrane and cell wall integrity, as the cluster "carbohydrate phosphorylation" / "pectin biosynthetic process" / "xylan biosynthetic process", and the two GO terms, "cell wall" and "plasma membrane" were filtered out (Figure 5). Since the lipid composition of the plasma membrane is sensitive to temperature fluctuations [10,13], not being able to maintain the plasma membrane's integrity poses a risk for membrane lesions, which can lead to cell death [11,13]. Meanwhile, pectin and xylan are two components of the plant cell wall [75]. It has been shown that cell wall softening is crucial for cell elongation and growth, while cell wall stiffening plays an important role in both abiotic and biotic stress tolerance [76-78]. Furthermore, modifications of the cell wall may trigger other downstream signaling events to activate defense pathways [79]. Filtering out this pathway from GO enrichment makes sense as electrolyte leakage, which measures the degree of membrane damage, was used as a parameter for mapping.

The third pathway appears to address dynamic molecular events involving DNA and RNA, as the cluster "chromosome" / "replisome" / "replication fork" / "nuclear lumen", and the cluster "nucleotide binding" / "ribonucleotide binding" / "nucleoside binding" / "anion binding" / "calcium ion binding" was filtered out (Figure 5). These clusters suggest that regulation of DNA replication and possibly chromatin structure play a role in cold stress tolerance responses in rice. Nucleosomes contain "nucleotide binding" proteins and their structure determines accessibility of DNA sequences in transcription, DNA replication, repair, and recombination [80-82]. Therefore, cold temperature mediated nucleosome remodeling might help establishing gene expression states involved in cold stress tolerance responses, while the term "ribonucleotide binding" suggests contributions of ATP-binding kinases and GTP-binding G-proteins in this process [83].

Taken together, the GO term enrichment helps further our understanding of how ROS and antioxidative activity contribute to maintaining membrane integrity and general survivability during cold stress exposure by playing roles in complex signaling networks, plasma membrane and cell wall architecture, and DNA replication, chromatin remodeling, and regulation of gene expression.

\section{Conclusions}

This study provides a novel and fine-tuned list of four types of cold tolerance trait QTL and associated candidate genes and genetic pathways in an important crop plant using 370 RPD1 O. sativa accessions and a GWAS-based mapping pipeline. We show that at the end of the chilling stress treatment, different levels of either enzymatic or nonenzymatic antioxidative activity predict the survivability potential of rice plants after a one-week recovery period. Rice breeders could use this ability of cold stressed rice plants to turn over ROS as a proxy to predict cold stress tolerance outcomes of their breeding lines. Interestingly, even with antioxidative activity as another filtering layer to investigate cold stress tolerance response mechanisms, numerous previously identified QTL regions were uncovered again. This indicates a close association between antioxidative activity and physiological cold stress tolerance response mechanisms. Within the QTL regions, an enrichment of genes belonging to the three pathways of signal transduction, maintenance of the plasma membrane and cell wall integrity, and nucleic acids metabolism, was identified at a high significance level. The high degree of overlap between antioxidant activity QTL and membrane integrity and overall seedling survivability QTL shows that an appropriate regulation of ROS homeostasis during cold stress exposure is critical for rice cold tolerance at the young seedling stage. A detailed investigation of candidate genes belonging to the three pathways, from SNP allele frequency analysis to transcriptomic studies, will help to improve cold tolerance potentials not only of Asian rice, but most likely, also of other important crop plants. 
Supplementary Materials: The following are available online at https: / www.mdpi.com/article/ 10.3390/genes12111700/s1, Figure S1: Box plots of mean values for four cold tolerance response phenotypes after a 7-day- $10^{\circ} \mathrm{C}$ chilling treatment for two cold check accessions: temperate japonica Krasnodarskij 3352 (KR/blue; cold tolerant check) and aus Carolino-164 (CA/red; cold sensitive check), Figure S2: Quantile-Quantile (QQ) plots of GWAS mapping runs for four cold stress tolerance response phenotypes using 370 RDP1 accessions, Figure S3: Correlation analysis of two cold stress tolerance response phenotypes between this study ( $x$-axis) and Shimoyama et al. 2020 [40] (y-axis), Figure S4: Distribution analysis of four cold stress tolerance response phenotypes for 370 RDP1 accessions, Figure S5: Distribution analysis of individual LTSS and EL activity phenotypes for three trials, Figure S6: Distribution analysis of individual CAT and ANT activity phenotypes for three trials, Figure S7: Box plots of mean values for CAT activity (A) and ANT activity (B) of 14-day-old seedlings for a subset of $70 \mathrm{RDP} 1$ accessions grown under warm temperature $\left(28^{\circ} \mathrm{C}\right.$ day $/ 25^{\circ} \mathrm{C}$ night) conditions, Table S1: Means, standard deviation, and variances of individual trials for four phenotyping assays using 370 RDP1 O. sativa accessions after a 7-day- $10{ }^{\circ} \mathrm{C}$ chilling treatment, Table S2: Summary of 120 quantitative trait loci (QTL) identified by GWAS mapping for four cold stress tolerance response traits using 370 RDP1 accessions, Table S3: Positions of published QTL overlapping with the $20 \mathrm{MP}$ QTL identified in this GWAS mapping study.

Author Contributions: Conceptualization, H.P. and M.S.; methodology, H.P.; software, H.P.; formal analysis, H.P. and M.S.; investigation, H.P.; resources, M.S.; writing—original draft preparation, H.P.; writing-review and editing, M.S.; visualization, H.P.; supervision, M.S.; project administration, M.S.; funding acquisition, M.S. All authors have read and agreed to the published version of the manuscript.

Funding: This research was funded by National Institute of Food and Agriculture-Agriculture and Food Research Initiative (NIFA-AFRI) grant number 2016-67013-24587 from the United States Department of Agriculture (USDA). H.P. was supported in part by Graduate Assistance in the Area of National Need (GAANN) grant number P200A150199 from the United States Department of Education (DoE).

Institutional Review Board Statement: Not applicable.

Informed Consent Statement: Not applicable.

Data Availability Statement: All data mentioned in this manuscript can be found in the Tables and Figures shown here and on the journal website as Supplementary Tables and Figures.

Acknowledgments: We are grateful to Marquette University graduate student, Naoki Shimoyama, and Marquette University former graduate student, Yao Shi, who shared their technical expertise in phenotyping cold stress-related assays and GWAS mapping. Marquette University graduate student Nasim Maghboli Balasjin is acknowledged for her technical expertise in growth media preparation.

Conflicts of Interest: The authors declare no conflict of interest.

\section{References}

1. Shi, Y.; Guo, E.; Wang, L.; Li, T.; Jiang, S.; Xiang, H.; Zhang, T.; Cheng, X.; Xhu, X.; Zhou, L. Effects of chilling at the booting and flowering stages on rice phenology and yield: A case study in Northeast China. J. Agron. Crop. Sci. 2021, 1-12.

2. Arshad, M.S.; Farooq, M.; Asch, F.; Krishna, J.S.V.; Prasad, P.V.V.; Siddique, K.H.M. Thermal stress impacts reproductive development and grain yield in rice. Plant Physiol. Biochem. 2017, 115, 57-72. [CrossRef]

3. Bodirsky, B.L.; Rolinski, S.; Biewald, A.; Weindl, I.; Popp, A.; Lotze-Campen, H. Global food demand scenarios for the 21st century. PLOS ONE 2015, 10, e0139201. [CrossRef] [PubMed]

4. Bajzelj, B.; Richards, K.S.; Allwood, J.M.; Smith, P.; Dennis, J.S.; Curmi, E.; Gilligan, C.A. Importance of food-demand management for climate mitigation. Nat. Clim. Chang. 2014, 4, 924-929. [CrossRef]

5. Zhang, H.; Li, Y.; Zhu, J.-K. Developing naturally stress-resistant crops for a sustainable agriculture. Nat. Plants 2018, 4, 989-996. [CrossRef] [PubMed]

6. Kumar, K.; Gambhir, G.; Dass, A.; Tripathi, A.K.; Singh, A.; Jha, A.K.; Yadava, P.; Choudhary, M.; Rakshit, S. Genetically modified crops: Current status and future prospects. Planta 2020, 251, 1-27. [CrossRef]

7. Wu, X.; Ning, F.; Hu, X.; Wang, W. Genetic modification for improving seed vigor is transitioning from model plants to crop plants. Front. Plant Sci. 2017, 8, 8. [CrossRef]

8. Sanghera, G.S.; Wani, S.H.; Hussain, W.; Singh, N.B. Engineering cold stress tolerance in crop plants. Curr. Genom. 2011, 12, 30. [CrossRef] [PubMed] 
9. Hoffman, L.; DaCosta, M.; Ebdon, J.S.; Watkins, E. Physiological changes during cold acclimation of perennial ryegrass accessions differing in freeze tolerance. Crop. Sci. 2010, 50, 1037-1047. [CrossRef]

10. Ritonga, F.N.; Su, C. Physiological and molecular mechanism involved in cold stress tolerance in plants. Plants 2020, 9, 560. [CrossRef]

11. Shi, Y.; Phan, H.; Liu, Y.; Cao, S.; Zhang, Z.; Chu, C.; Schläppi, M.R. Glycosyltransferase OsUGT90A1 helps protect the plasma membrane during chilling stress in rice. J. Exp. Bot. 2020, 71, 2723-2739. [CrossRef]

12. Takahashi, D.; Li, B.; Nakayama, T.; Kawamura, Y.; Uemura, U. Plant plasma membrane proteomics for improving cold tolerance. Front. Plant Sci. 2013, 4, 90. [CrossRef] [PubMed]

13. Barrero-Sicilia, C.; Silvestre, S.; Haslam, R.P.; Michaelson, L.V. Lipid remodelling: Unravelling the response to cold stress in Arabidopsis and its extremophile relative Eutrema salsugineum. Plant Sci. 2017, 263, 194-200. [CrossRef] [PubMed]

14. Banerjee, A.; Aryadeep, R. Abiotic stress, generation of reactive oxygen species, and their consequences: An overview. In Reactive Oxygen Species in Plants: Boon or Bane? Wiley: Hoboken, NJ, USA, 2018; pp. 23-50.

15. Dreyer, A.; Karl-Josef, D. Reactive oxygen species and the redox-regulatory network in cold stress acclimation. Antioxidants 2018, 7, 169. [CrossRef]

16. Gupta, D.K.; José, M.P.; Francisco, J.C. (Eds.) Reactive Oxygen Species and Oxidative Damage in Plants under Stress; Springer: Berlin/Heidelberg, Germany, 2015.

17. Caverzan, A.; Alice, C.; Sandra, P.B. Reactive oxygen species and antioxidant enzymes involved in plant tolerance to stress. SHANKER AK E SHANKER C. Abiotic and Biotic Stress in Plants-Recent Advances and Future Perspectives; InTechOpen Ltd.: London, UK, 2016; pp. $463-480$.

18. Caverzan, A.; Passaia, G.; Barcellos, S.; Carolina, R.; Ribeiro, W.; Lazzarotto, F.; Margis-Pinheiro, M. Plant responses to stresses: Role of ascorbate peroxidase in the antioxidant protection. Genet. Mol. Biol. 2012, 35, 1011-1019. [CrossRef] [PubMed]

19. Bela, K.; Horváth, E.; Gallé, Á.; Szabados, L.; Tari, I.; Csiszár, J. Plant glutathione peroxidases: Emerging role of the antioxidant enzymes in plant development and stress responses. J. Plant Physiol. 2015, 176, 192-201. [CrossRef]

20. Mhamdi, A.; Queval, G.; Chaouch, S.; Vanderauwera, S.; Van Breusegem, F.; Noctor, G. Catalase function in plants: A focus on Arabidopsis mutants as stress-mimic models. J. Exp. Bot. 2010, 61, 4197-4220. [CrossRef]

21. Alam, N.B.; Ajit, G. Comprehensive analysis and transcript profiling of Arabidopsis thaliana and Oryza sativa catalase gene family suggests their specific roles in development and stress responses. Plant Physiol. Biochem. 2018, 123, 54-64. [CrossRef]

22. Vighi, I.L.; Benitez, L.C.; do Amaral, M.N.; Auler, P.A.; Moraes, G.P.; Rodrigues, G.S.; Da Maia, L.C.; Pinto, L.S.; Braga, E.J. Changes in gene expression and catalase activity in Oryza sativa L. under abiotic stress. Genet. Mol. Res. 2016, 15, 1-15. [CrossRef]

23. Azpilicueta, C.E.; Pena, L.B.; Tomaro, M.L.; Gallego, S.M. Modifications in catalase activity and expression in developing sunflower seedlings under cadmium stress. Redox Rep. 2008, 13, 40-46. [CrossRef]

24. Moriwaki, T.; Yamamoto, Y.; Aida, T.; Funahashi, T.; Shishido, T.; Asada, M.; Prodhan, S.H.; Komamine, A.; Motohashi, T. Overexpression of the Escherichia coli catalase gene, katE, enhances tolerance to salinity stress in the transgenic indica rice cultivar, BR5. Plant Biotechnol. Rep. 2008, 2, 41-46. [CrossRef]

25. Liu, Y.; Tikunov, Y.; Schouten, R.E.; Marcelis, L.F.M.; Visser, R.G.F.; Bovy, A. Anthocyanin biosynthesis and degradation mechanisms in Solanaceous vegetables: A review. Front. Chem. 2018, 6, 52. [CrossRef] [PubMed]

26. Landi, M.; Tattini, M.; Kevin, S.G. Multiple functional roles of anthocyanins in plant-environment interactions. Environ. Exp. Bot. 2015, 119, 4-17. [CrossRef]

27. Goufo, P.; Henrique, T. Rice antioxidants: Phenolic acids, flavonoids, anthocyanins, proanthocyanidins, tocopherols, tocotrienols, $\gamma$-oryzanol, and phytic acid. Food Sci. Nutr. 2014, 2, 75-104. [CrossRef]

28. Kovinich, N.; Kayanja, G.; Chanoca, A.; Riedl, K.; Otegui, M.S.; Grotewold, E. Not all anthocyanins are born equal: Distinct patterns induced by stress in Arabidopsis. Planta 2014, 240, 931-940. [CrossRef] [PubMed]

29. Zhu, W.; Jia, Q.; Wang, Y.; Zhang, Y.; Xia, M. The anthocyanin cyanidin-3-O- $\beta$-glucoside, a flavonoid, increases hepatic glutathione synthesis and protects hepatocytes against reactive oxygen species during hyperglycemia: Involvement of a cAMPPKA-dependent signaling pathway. Free. Radic. Biol. Med. 2012, 52, 314-327. [CrossRef]

30. Zilic, S. Phenolic compounds of wheat. Their content, antioxidant capacity and bioaccessibility. MOJ Food Process. Technol. 2016, 2, 00037. [CrossRef]

31. Chutipaijit, S.; Suriyan, C.; Kanokporn, S. High contents of proline and anthocyanin increase protective response to salinity in 'Oryza sativa' L. spp. 'indica'. Aust. J. Crop. Sci. 2011, 5, 1191-1198.

32. Kovinich, N.; Kayanja, G.; Chanoca, A.; Riedl, K.; Otegui, M.S.; Grotewold, E. Abiotic stresses induce different localizations of anthocyanins in Arabidopsis. Plant Signal. Behav. 2015, 10, e1027850. [CrossRef]

33. Tisarum, R.; Theerawitaya, C.; Samphumphuang, T.; Cha-um, S. Regulation of anthocyanin accumulation in rice (Oryza sativa L. subsp. indica) using MgSO4 spraying and low temperature. Arch. Agron. Soil Sci. 2018, 64, 1663-1677. [CrossRef]

34. Zhu, J.-J.; Li, Y.-R.; Liao, J.-X. Involvement of anthocyanins in the resistance to chilling-induced oxidative stress in Saccharum officinarum L. leaves. Plant Physiol. Biochem. 2013, 73, 427-433. [CrossRef]

35. Zhao, K.; Wright, M.; Kimball, J.; Eizenga, G.; McClung, A.; Kovach, M.; Tyagi, W.; Ali, M.L.; Tung, C.-W.; Reynolds, A.; et al. Genomic diversity and introgression in O. sativa reveal the impact of domestication and breeding on the rice genome. PLoS ONE 2010, 5, e10780. 
36. Agrama, H.A.; Eizenga, G.C.; Yan, W.E. Association mapping of yield and its components in rice cultivars. Mol. Breed. 2007, 19, 341-356. [CrossRef]

37. Schläppi, M.R.; Jackson, A.K.; Eizenga, G.C.; Wang, A.; Chu, C.; Shi, Y.; Shimoyama, S.; Boykin, D.L. Assessment of five chilling tolerance traits and GWAS mapping in rice using the USDA mini-core collection. Front. Plant Sci. 2017, 8, 957. [CrossRef] [PubMed]

38. McCouch, S.R.; Wright, M.H.; Tung, C.-W.; Maron, L.G.; McNally, K.L.; Fitzgerald, M.; Namrata Singh, N.; DeClerck, G.; Agosto-Perez, F.; Korniliev, P.; et al. Open access resources for genome-wide association mapping in rice. Nat. Commun. 2016, 7, 1-14. [CrossRef] [PubMed]

39. Spindel, J.E.; Begum, H.; Akdemir, D.; Collard, B.; Redoña, E.; Jannink, J.L.; McCouch, S. Genome-wide prediction models that incorporate de novo GWAS are a powerful new tool for tropical rice improvement. Heredity 2016, 116, 395-408. [CrossRef]

40. Shimoyama, N.; Johnson, M.; Beaumont, A.; Schläppi, M. Multiple cold tolerance trait phenotyping reveals shared quantitative trait loci in Oryza sativa. Rice 2020, 13, 1-17. [CrossRef] [PubMed]

41. Kumar, V.; Singh, A.; Mithra, S.V.M.; Krishnamurthy, S.L.; Parida, S.K.; Jain, S.; Tiwari, K.K.; Kumar, P.; Rao, A.R.; Sharma, S.K.; et al. Genome-wide association mapping of salinity tolerance in rice (Oryza sativa). DNA Res. 2015, 22, 133-145. [CrossRef]

42. Li, X.; Guo, Z.; Lv, Y.; Xiang Cen, X.; Ding, X.; Wu, H.; Li, X.; Huang, J.; Xiong, L. Genetic control of the root system in rice under normal and drought stress conditions by genome-wide association study. PLoS Genet. 2017, 13, e1006889. [CrossRef]

43. Li, C.; Wang, D.; Peng, S.; Chen, Y.; Su, P.; Chen, J.; Zheng, L.; Tan, X.; Liu, J.; Xiao, Y.; et al. Genome-wide association mapping of resistance against rice blast strains in South China and identification of a new Pik allele. Rice 2019, 12, 1-9. [CrossRef]

44. Eizenga, G.C.; Ali, M.L.; Bryant, R.B.; Yeater, K.M.; McClung, A.M.; McCouch, S.R. Registration of the rice diversity panel 1 for genome wide association studies. J. Plant Regist. 2014, 8, 109-116. [CrossRef]

45. Chen, H.; Xie, W.; He, H.; Yu, H.; Chen, W.; Li, J.; Yu, R.; Yao, Y.; Zhang, W.; He, Y.; et al. A high-density SNP genotyping array for rice biology and molecular breeding. Mol. Plant 2014, 7, 541-553. [CrossRef] [PubMed]

46. Lv, Y.; Guo, Z.; Li, X.; Ye, H.; Li, X.; Xiong, L. New insights into the genetic basis of natural chilling and cold shock tolerance in rice by genome-wide association analysis. Plant Cell Environ. 2016, 39, 556-570. [CrossRef] [PubMed]

47. Wang, D.; Liu, J.; Li, C.; Kang, H.; Wang, Y.; Tan, X.; Liu, M.; Deng, Y.; Wang, Z.; Liu, Y.; et al. Genome-wide association mapping of cold tolerance genes at the seedling stage in rice. Rice 2016, 9, 1-10. [CrossRef] [PubMed]

48. Kim, S.-I.; Thomas, H.T. Evaluation of seedling cold tolerance in rice cultivars: A comparison of visual ratings and quantitative indicators of physiological changes. Euphytica 2011, 178, 437-447. [CrossRef]

49. Kazemi-Shahandashti, S.-S.; Reza, M.-A. Global insights of protein responses to cold stress in plants: Signaling, defence, and degradation. J. Plant Physiol. 2018, 226, 123-135. [CrossRef]

50. Wang, X.; Fang, G.; Li, Y.; Ding, M.; Gong, H.; Li, Y. Differential antioxidant responses to cold stress in cell suspension cultures of two subspecies of rice. Plant Cell Tissue Organ Cult. (PCTOC) 2013, 113, 353-361. [CrossRef]

51. Pradhan, S.K.; Pandit, E.; Nayak, D.K.; Behera, L.; Mohapatra, T. Genes, pathways and transcription factors involved in seedling stage chilling stress tolerance in indica rice through RNA-Seq analysis. BMC Plant Biol. 2019, 19, 1-17. [CrossRef]

52. Chawade, A.; Lindlöf, A.; Olsson, B.; Olsson, O. Global expression profiling of low temperature induced genes in the chilling tolerant japonica rice Jumli Marshi. PLoS ONE 2013, 8, e81729. [CrossRef]

53. Shen, C.; Li, D.; He, R.; Fang, Z.; Xia, Y.; Gao, J.; Shen, H.; Cao, M. Comparative transcriptome analysis of RNA-seq data for cold-tolerant and cold-sensitive rice genotypes under cold stress. J. Plant Biol. 2014, 57, 337-348. [CrossRef]

54. Zhang, J.; Luo, W.; Zhao, Y.; Xu, Y.; Song, S.; Chong, K. Comparative metabolomic analysis reveals a reactive oxygen speciesdominated dynamic model underlying chilling environment adaptation and tolerance in rice. New Phytol. 2016, 211, 1295-1310. [CrossRef] [PubMed]

55. Zhang, Q.; Chen, Q.; Wang, S.; Hong, Y.; Wang, Z. Rice and cold stress: Methods for its evaluation and summary of cold tolerance-related quantitative trait loci. Rice 2014, 7, 1-12. [CrossRef] [PubMed]

56. Han, B.; Ma, X.; Cui, D.; Wang, Y.; Geng, L.; Cao, G.; Zhang, H.; Han, L. Comprehensive evaluation and analysis of the mechanism of cold tolerance based on the transcriptome of weedy rice seedlings. Rice 2020, 13, 1-14. [CrossRef] [PubMed]

57. Ouyang, S.; Zhu, W.; Hamilton, J.; Lin, H.; Campbell, M.; Childs, K.; Thibaud-Nissen, F.; Malek, R.L.; Lee, Y.; Zheng, L.; et al. The TIGR Rice Genome Annotation Resource: Improvements and new features. Nucleic Acids Res. 2007, 35, D883-D887. [CrossRef]

58. Yao, W.; Li, G.; Yu, Y.; Ouyang, Y. funRiceGenes dataset for comprehensive understanding and application of rice functional genes. Gigascience 2018, 7, gix119. [CrossRef] [PubMed]

59. Zhang, Z.; Li, J.; Pan, Y.; Li, J.; Shi, H.; Zeng, Y.; Guo, H.; Yang, S.; Zheng, W.; Yu, J.; et al. Natural variation in CTB4a enhances rice adaptation to cold habitats. Nat. Commun. 2017, 8, 1-13. [CrossRef]

60. Saito, K.; Hayano-Saito, Y.; Maruyama-Funatsuki, W.; Sato, Y.; Kato, A. Physical mapping and putative candidate gene identification of a quantitative trait locus Ctb1 for cold tolerance at the booting stage of rice. Theor. Appl. Genet. 2004, 109, 515-522. [CrossRef] [PubMed]

61. Saito, K.; Hayano-Saito, Y.; Kuroki, M.; Sato, Y. Map-based cloning of the rice cold tolerance gene Ctb1. Plant Sci. 2010, 179, 97-102. [CrossRef]

62. Lu, C.-A.; Huang, C.-K.; Huang, W.-S.; Huang, T.-S.; Liu, H.-Y.; Chen, Y.-F. DEAD-box RNA helicase 42 plays a critical role in pre-mRNA splicing under cold stress. Plant Physiol. 2020, 182, 255-271. [CrossRef] 
63. Huang, H.-J.; Fu, S.-F.; Tai, Y.-H.; Chou, W.-C.; Huang, D.-D. Expression of Oryza sativa MAP kinase gene is developmentally regulated and stress-responsive. Physiol. Plant. 2002, 114, 572-580. [CrossRef]

64. Agrawal, G.K.; Randeep, R.; Hitoshi, I. Isolation of novel rice (Oryza sativa L.) multiple stress responsive MAP kinase gene, OsMSRMK2, whose mRNA accumulates rapidly in response to environmental cues. Biochem. Biophys. Res. Commun. 2002, 294, 1009-1016. [CrossRef]

65. Xie, G.; Hideki, K.; Ryozo, I. Biochemical identification of the OsMKK6-OsMPK3 signalling pathway for chilling stress tolerance in rice. Biochem. J. 2012, 443, 95-102. [CrossRef] [PubMed]

66. Zhang, H.; Ni, L.; Liu, Y.; Wang, Y.; Zhang, A.; Tan, M.; Jiang, M. The C2H2-type Zinc Finger Protein ZFP182 is Involved in Abscisic Acid-Induced Antioxidant Defense in Rice, F.J. Integr. Plant Biol. 2012, 54, 500-510. [CrossRef] [PubMed]

67. Guo, Z.; Cai, L.; Chen, Z.; Wang, R.; Zhang, L.; Guan, S.; Zhang, S.; Ma, W.; Liu, C.; Pan, G. Identification of candidate genes controlling chilling tolerance of rice in the cold region at the booting stage by BSA-Seq and RNA-Seq. R. Soc. Open Sci. 2020, 7, 201081. [CrossRef]

68. Ma, Q.; Dai, X.; Xu, Y.; Guo, J.; Liu, Y.; Chen, N.; Xiao, J.; Zhang, D.; Xu, Z.; Zhang, X.; et al. Enhanced tolerance to chilling stress in OsMYB3R-2 transgenic rice is mediated by alteration in cell cycle and ectopic expression of stress genes. Plant Physiol. 2009, 150, 244-256. [CrossRef]

69. Dai, X.; Xu, Y.; Ma, Q.; Xu, W.; Wang, T.; Xue, Y.; Chong, K. Overexpression of an R1R2R3 MYB gene, OsMYB3R-2, increases tolerance to freezing, drought, and salt stress in transgenic Arabidopsis. Plant Physiol. 2007, 143, 1739-1751. [CrossRef]

70. Yu, Y.; Li, Q.-F.; Zhang, J.-P.; Zhang, F.; Zhou, Y.-F.; Feng, Y.-Z.; Chen, Y.-Q.; Zhang, Y.-C. Laccase-13 regulates seed setting rate by affecting hydrogen peroxide dynamics and mitochondrial integrity in rice. Front. Plant Sci. 2017, 8, 1324. [CrossRef] [PubMed]

71. Li, Z.; Wang, B.; Zhang, Z.; Luo, W.; Tang, Y.; Niu, Y.; Chong, K.; Xu, Y. OsGRF6 interacts with SLR1 to regulate OsGA2ox1 expression for coordinating chilling tolerance and growth in rice. J. Plant Physiol. 2021, 260, 153406. [CrossRef]

72. Kim, S.-H.; Choi, H.-S.; Cho, Y.-C.; Kim, S.-R. Cold-responsive regulation of a flower-preferential class III peroxidase gene, OsPOX1, in rice (Oryza sativa L.). J. Plant Biol. 2012, 55, 123-131. [CrossRef]

73. Hashimoto, M.; Setsuko, K. Proteomic analysis of rice seedlings during cold stress. Proteomics 2007, 7, 1293-1302. [CrossRef]

74. Bonnecarrère, V.; Borsani, O.; Díaz, P.; Capdevielle, F.; Blanco, P.; Monza, J. Response to photoxidative stress induced by cold in japonica rice is genotype dependent. Plant Sci. 2011, 180, 726-732. [CrossRef]

75. Lin, F.; Manisseri, C.; Fagerström, A.; Peck, M.L.; Vega-Sánchez, M.E.; Williams, B.; Chiniquy, D.M.; Saha, P.; Pattathil, S.; Conlin, B.; et al. Cell wall composition and candidate biosynthesis gene expression during rice development. Plant Cell Physiol. 2016, 57, 2058-2075. [CrossRef] [PubMed]

76. Tenhaken, R. Cell wall remodeling under abiotic stress. Front. Plant Sci. 2015, 5, 771. [CrossRef]

77. Novakovic, L.; Guo, T.; Bacic, A.; Sampathkumar, A.; Johnson, K.L. Hitting the wall—Sensing and signaling pathways involved in plant cell wall remodeling in response to abiotic stress. Plants 2018, 7, 89. [CrossRef]

78. Wolf, S.; Steffen, G. Growth control by cell wall pectins. Protoplasma 2012, 249, 169-175. [CrossRef] [PubMed]

79. Prathi, N.B.; Palit, P.; Madhu, P.; Ramesh, M.; Laha, G.S.; Balachandran, S.M.; Madhav, M.S.; Sundaram, R.M.; Mangrauthia, S.K. Proteomic and transcriptomic approaches to identify resistance and susceptibility related proteins in contrasting rice genotypes infected with fungal pathogen Rhizoctonia solani. Plant Physiol. Biochem. 2018, 130, 258-266. [CrossRef]

80. Cutter, A.R.; Jeffrey, J.H. A brief review of nucleosome structure. FEBS Lett. 2015, 589, 2914-2922. [CrossRef] [PubMed]

81. Andrews, A.J.; Karolin, L. Nucleosome structure (s) and stability: Variations on a theme. Annu. Rev. Biophys. 2011, 40, 99-117. [CrossRef]

82. McGinty, R.K. Nucleosome structure and function. Chem. Rev. 2015, 115, 2255-2273. [CrossRef]

83. Bhardwaj, D.; Suman, L.; Narendra, T. Can G-proteins be the key proteins for overcoming environmental stresses and increasing crop yield in plants. In Plant Acclimation to Environmental Stress; Springer: New York, NY, USA, 2013; pp. 461-482. 